\title{
FATORES DE GERAÇÃO E USO DA PAISAGEM DE CENTROS HISTÓRICOS E ARREDORES O CASO DE RECIFE
}

KATHIA MARIA FERNANDES*

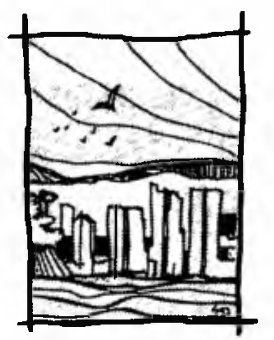

O trabalho aqui apresentado compreende a $1^{\mathrm{a}}$ parte de minha Tese de Graduação Interdisciplinar TGI - 1986, que buscou ordenar um trabalho inteiramente voltado para o desenho urbano, fazendo uso de todos os elementos de apoio em pesquisas de campo e em material bibliográfico, nas áreas histórica e de planejamento estrutural urbano, atendo-se também às características sociais do espaço em questão.

O trabalho se complementa com uma segunda fase de propostas de intervenção espacial na área de estudo, criando, através de legislação específica, um novo desenho volumétrico definindo uma configuração particular para toda a área, atuando a nível macro e micro nos espaços livres e áreas de circulação, na estrutura viária, na regulamentação dos usos e estabelecendo a quadra como unidade elementar da paisagem dentro do projeto. Foram também utilizados parâmetros de seleção das áreas de intervenção baseados na importância dos conjuntos históricos existentes não descaracterizados.

\section{ANÁLISE TEMÁTICA}

O presente trabalho tem como objetivo trazer, através do estudo de um exemplo específico, a questão do desenho e do redesenho de centros urbanos de caráter histórico.

Segundo Jan Thanghe, o homem confronta-se hoje com a desintegração urbana de maior extensão já conhecida na história através do conflito:

Meio Ambiente x Industrialização Tecnológica

Crescimento econômico ilimitado

Crescimento das atividades urbanas e da escala da cidade 
Em outras palavras, a organização das cidades de hoje perde-se pelo não atendimento, em termos espaciais, da demanda gerada pelos setores produtivos da sociedade, além do crescimento da mesma.

Dentro deste quadro, as atenções são voltadas para áreas urbanas mais "antigas", de caráter histórico, e com ocupação, por vezes, de baixo aproveitamento. Imagina-se que tais áreas sejam "reservas em potencial" para expansão e adensamento, observadas segundo parâmetros exclusivamente econômicosespeculativos.

Embora não haja hoje oposições fundamentais entre as necessidades e as aspirações do habitat humano e as estruturas das cidades históricas, a adaptação destas estruturas e suas edificações é raramente levada em consideração.

O conceito de preservação do patrimônio histórico diz que o homem não deve perder sua memória física e cultural. Para tanto, este deve esforçar-se para evitar descaracterizações e o desaparecimento de documentos da história e da origem das civilizações. E, assim como o homem moderno precisa de uma cidade igualmente moderna, dinâmica, funcional, perfeitamente adaptada às exigências deste homem e do seu estilo de vida, os conjuntos são o documento edificado da sociedade que os criam; espelham as exigências daquelas sociedades, daquelas épocas passadas.

As posturas usuais de intervenção em áreas com este caráter são, por vezes, opostas: Por um lado, pretende-se restaurar a imagem inicial de uma área, programando-se, para isso, que a construção de novas edificações siga totalmente as características das antigas. Por outro lado, preserva-se com a intenção de "imobilizar uma cena", ou seja, não há qualquer tipo de intervenção: não se constrói, não se restaura, não se demole; tudo deve permanecer como está.

A grande tradição na preservação de bens culturais históricos no Brasil é o tombamento de edificações isoladas, não se levando em conta sua implantação ou seu entorno. A preservação "digna" de conjuntos históricos tem poucos exemplos nas cidades brasileiras, que sobrevivem graças à iniciativa particular de usuários e proprietários (como é o caso dos conjuntos históricos de Salvador, São Luis, Olinda e Ouro Preto, por exemplo). Na maior parte dos casos, esta é a única forma de manutenção e conservação existente, uma vez que a intenção de preservação por parte dos órgãos públicos em geral se encerra quando se cria a lei de tombamento de um edifício ou área, e os recursos para a manutenção e/ou restauração e/ou revitalização destes são inexistentes ou desviados para suprir setores mais carentes da administração pública. 
Na realidade, é necessário o conhecimento de todo o meio ambiente (urbano e/ou rural) da região onde se insere a obra ou área de valor histórico para se saber as possibilidades de êxito de uma política de revitalização urbana integrada. A região deve possuir estabilidade econômica e deve estar preparada para dispor de um plano estrutural que possibilite uma política de adaptação.

Partindo dessas premissas, analisa-se aqui uma área de alto valor histórico; o centro urbano de uma metrópole brasileira, pólo regional de atração, que possui características físicas, ambientais e sociais extremamente peculiares: a área central de Recife, mais especificamente, o seu centro histórico.

\section{QUESTÕES}

As áreas de valor histórico possuem um potencial econômico de teor turístico, que é geralmente levado em conta no direcionamento de sua preservação. Mas, olhando sob este aspecto, tais áreas transformam-se apenas no cenário de épocas passadas, um grande museu a céu aberto. $O$ turismo em áreas históricas não tem sido um fator suficientemente forte para que estas possuam estabilidade econômica para sua manutenção e revitalização. A conservação cujo único objetivo é embelezar, baseada no gosto de pretensos entusiastas estéticos, que de maneira nenhuma cumpre qualquer necessidade social ou humana, é tão fatal para as políticas de continuidade quanto a demolição da herança (cultural, arquitetônica, etc.). Isto acontece porque trata-se fundamentalmente de uma questão de adaptação da área histórica às necessidades reais do homem de hoje.

O uso a ser dado aos edifícios merece cuidados especiais: manter os usos existentes pode significar estagnação, a não ser que hajam alterações a nível da estrutura de circulação e do sistema de espaços livres da área. Por outro lado, a mudança radical de uso deve estar de acordo com uma política para as áreas adjacentes, ou mesmo para toda a cidade. Deve haver, ainda, a comunhão entre a função e o caráter estético dos edifícios.

A resolução do sistema de circulação leva primeiramente ao sistema viário: "o trânsito é uma função derivada das atividades urbanas. Apenas se controlando as funções urbanas se pode controlar o trânsito e, ao mesmo tempo, respeitar a rigidez da estrutura física da cidade" Porém, o trânsito também é fator importante para estimular a vitalidade geral da cidade.

O segundo entrave à circulação é a invasão de áreas centrais pelos ambulantes. Apesar de todas as críticas feitas a este modelo de ocupação, a sua retirada, em alguns locais, poderá significar o empobrecimento social e a deterioração dos mesmos. Perde-se a característica que dava vitalidade a estes, um elemento pitoresco e peculiar no contexto da área e da cidade. 
Avaliar a capacidade de mudança da cidade, mantendo-se o seu caráter, buscando as melhores formas de intervenção para cada caso deve ser. enfim, o objetivo primordial de todo estudo de revitalização de áreas de valor histórico. E. para que um estudo tenha êxito, é necessário que se compreenda os porquês da situação encontrada na área, além de estabelecer um método de interpretação da paisagem que use da sensibilidade visual e física além dos usuais métodos de coleta de dados demográficos, históricos, econômicos e sociais; os "dados de gabinete"

O conjunto não deve ser estudado e percebido através de uma visão historicista, e sim como um agrupamento de elementos atemporais.

\section{ESTUDO DE CASO RESUMO DA SITUAÇÃO ATUAL}

O Recife apresenta-se como um exemplo de centro formado por conjuntos arquitetônicos de diferentes époças dispostos lado a lado, submetidos a uma legislação de preservação recente 1980 , e que lhes impõe como norma as características arquitetônicas e espaciais da mais antiga, colonial. Sua estrutura de circulação mantém uma trama urbana dos séculos XVII e XVIII, mas atende às exigências funcionais, sociais, econômicas, administrativas de uma cidade moderna. Dentro deste contexto, unem-se ainda a falta de espaços livres para circulação, lazer ou expansão, aliada à inexistência de um sistema de manutenção adequado à área e à progressiva expulsão dos moradores em função da expansão comercial.

Tais elementos desencadearam um processo de crise e deterioração da área central, que vê também suas atividades de centro polarizador migrarem para outros pontos da cidade, deixando para trás não um novo uso, mas um grande número de imóveis fechados e vazios.

O estudo da paisagem fornece, então, os dados para a compreensão das forças atuantes na área, presentes e passadas e a numeração dos problemas existentes e dos elementos que os causaram.

\section{O ESTUDO DE CASO - RECIFE}

\section{EVOLUÇÃO HISTÓRICA E DELIMITAÇÃO DA ÁREA DE ESTUDO}

"O Recife foi erigido sob dominação holandesa em Pernambuco, norteando-se por planos cujo traçado seguia orientação semelhante às cidades costeiras da Holanda, e cidades fundadas por estes em sua atuação comercial colonizadora (Batávia, em Java e Nova Amsterdam, na Ilha de Manhattan)." 
Foram os próprios holandeses que iniciaram um processo de obtenção de novas áreas de expansão para o então aldeamento de pescadores e comerciantes. implantado em uma região alagadiça, sobre ilhas, totalmente à mercê das enchentes do rio e da ferocidade do mar. Através de um sistema de diques, aterros e canais, foram conquistadas novas áreas. Também se construíram pontes entre as ilhas e empreenderam-se vários melhoramentos na área, além da formulação de normas para a construção de novas edificações e diversos monumentos.

O centro inicial da cidade em formação era composto, a princípio, pelo próprio bairro do Recife, dada a sua proximidade com o porto do Recife, e, posteriormente, também pelo bairro de Santo Antonio. Os bairros adjacentes, que hoje também configuram a imagem de "centro do Recife" permaneceram por muito tempo ainda bairros apenas residenciais, no caso, São José e Boa Vista. (Ilustração 1)

Ilustração 1 Evolução das Atividades Centrais

EVOLUÇĀO DAS ATIVIDADES CENTRAIS

I. COMERCIO LIGADO AO PORTO

BOA VISTA

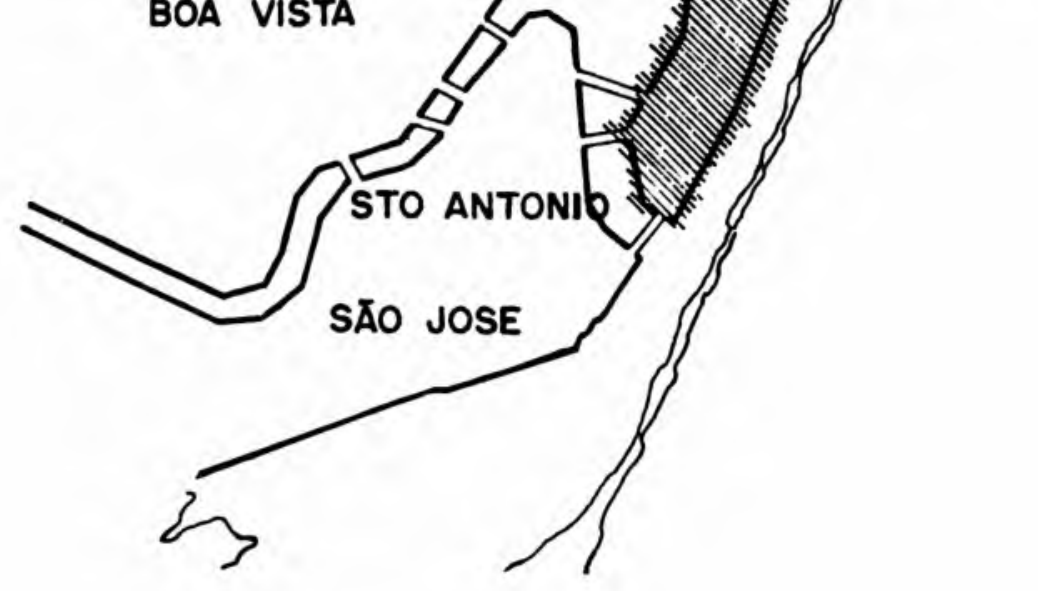


2 CRESCIMENTO DA VILA FORTALECIMENTO DO ENTREPOSTO COMERCIAL

3 SITUACAO ATUAL- IMPÖRTANCIA TREGGONAL

VIA PERIMETRAL

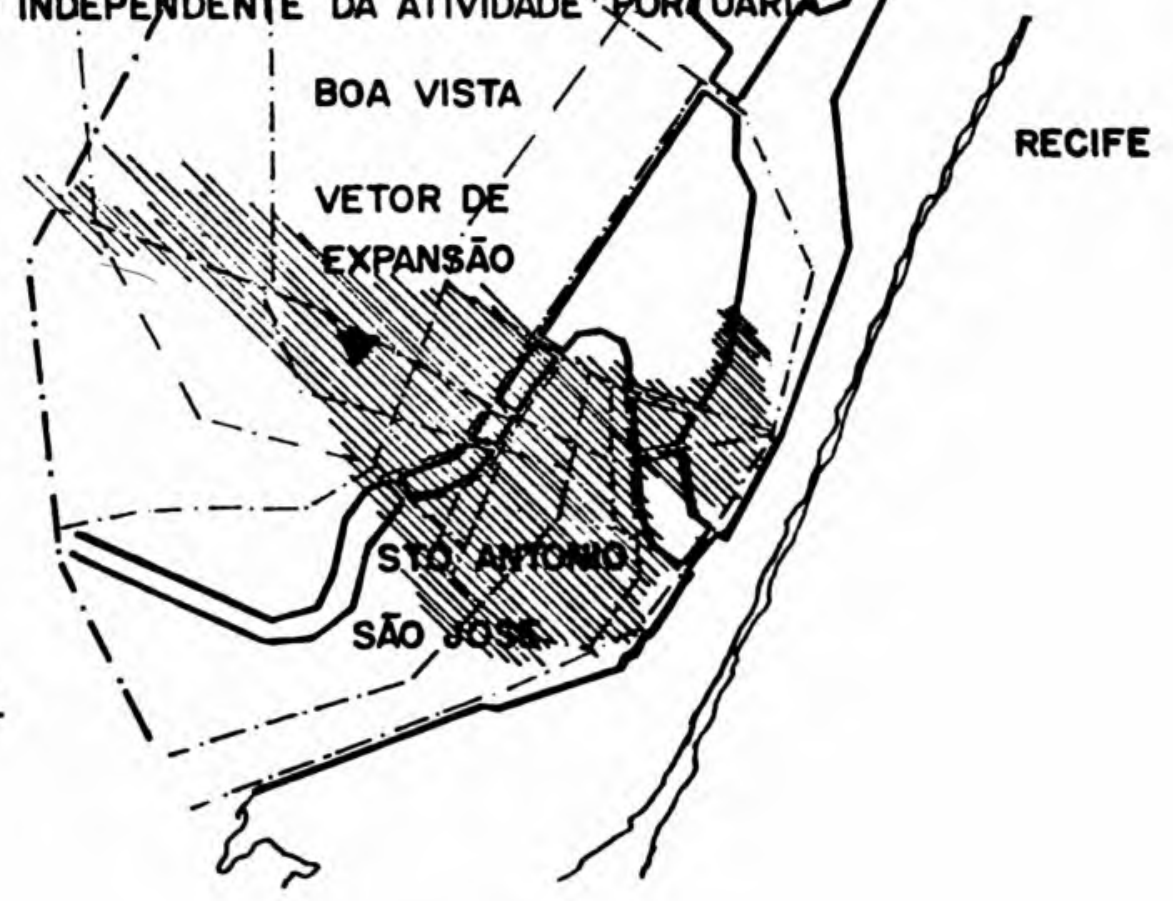


A cidade atualmente tem sua estrutura organizada através de eixos viários e corredores de atividades múltiplas que unem subcentros de serviços e comércio locais complementares ao núcleo central. (Ilustração 2)

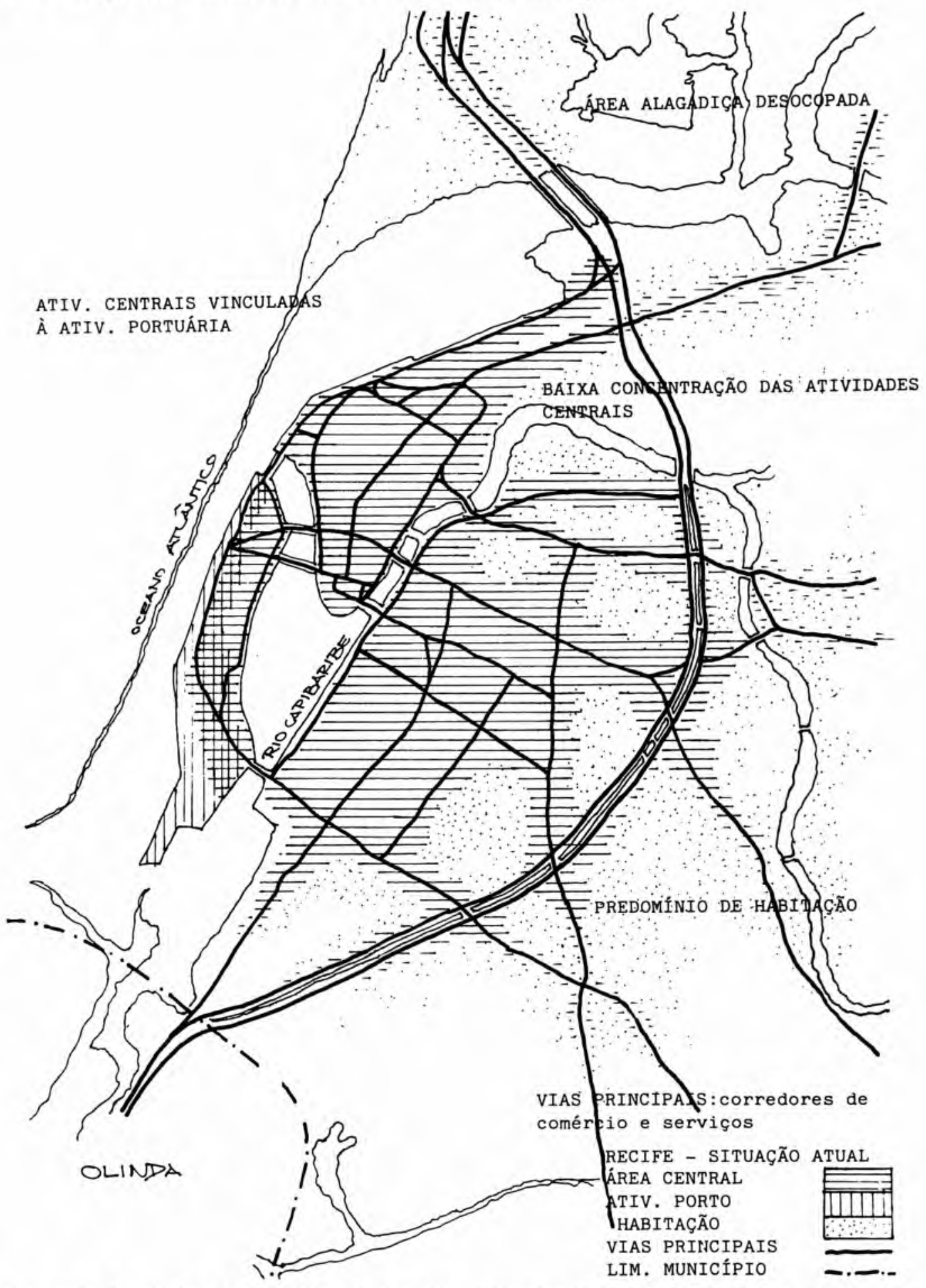

Ilustração 2 - Atividades Centrais Vinculadas à Atividade Portuária 
Toda a cidade tem a importância de pólo de atração regional, com grande contingente de migrantes do interior e de outros estados, toda uma população subempregada ou desempregada, de renda insignificante, precariamente instalada. Esta mesma população dá à cidade a característica do pólo regional de cultura popular, visível através da invasão do comércio ambulante, a princípio artesanal, mas que hoje oferece uma grande diversidade de produtos tornando-se uma força competitiva com o comércio tradicionalmente estabelecido, uma vez que a mercadoria vai para onde está o pedestre, "para o meio das ruas" e é vendida a preços mais atrativos.

Como foco de estudo, delimitou-se, no centro, uma área correspondente aos bairros de Santo Antonio e São José. Trata-se da área mais ativa da cidade, unindo os setores comercial e financeiro, abrigando as forças que dominam, organizam e direcionam a vida das cidades, o que, aliás, é um fato historicamente comprovado na área: o comércio (portuário) e a Igreja (igrejas, conventos, seminários, ordens terceiras, etc.), crescimento do comércio e do poder administrativo, e posteriormente o surgimento e ascensão dos serviços públicos e privados. (llustração 3)

\section{ESTRUTURA URBANA}

A área em questão é a de maior significado histórico da cidade, tratando-se da antiga Ilha de Antonio Vaz, sob a forma de um conjunto heterogêneo composto de subconjuntos homogêneos, representação fiel do desenvolvimento da cidade. A trama urbana remonta aos séculos XVII e XVIII com ruas estreitas, por vezes sinuosas, que se abrem em pátios e praças, antigos terreiros das igrejas, tradicionalmente utilizados pela população como pontos de reunião, em cerimônias cívicas e festividades religiosas e profanas, fazendo às vezes também de centro comercial, praça do mercado, em alguns casos.

Havia, como há ainda hoje, diferentes atividades num mesmo local, exercidas em espaços temporais diversos.

A modificação da estrutura da cidade tem se processado através dos séculos: o bairro do Recife, por exemplo, foi totalmente remodelado segundo a corrente haussmaniana, substituindo a paisagem colonial brasileira pelo Neoclassicismo dominante na época. É esta fórmula de transformação radicalizada, que destrói para depois reconstruir, criando grandes eixos visuais, avenidas largas, e padronização da altura e do desenho das edificações, que vem sendo aplicada à cidade até os nossos dias, como é o caso da criação do eixo da av. Guararapes e av. Conde da Boa Vista, em um plano da década de 50, e da construção da av. Dantas Barreto, em princípios da década de 70. 
Ilustraçāo 3 - O Centro do Recife - Delimitação da Área de Estudo

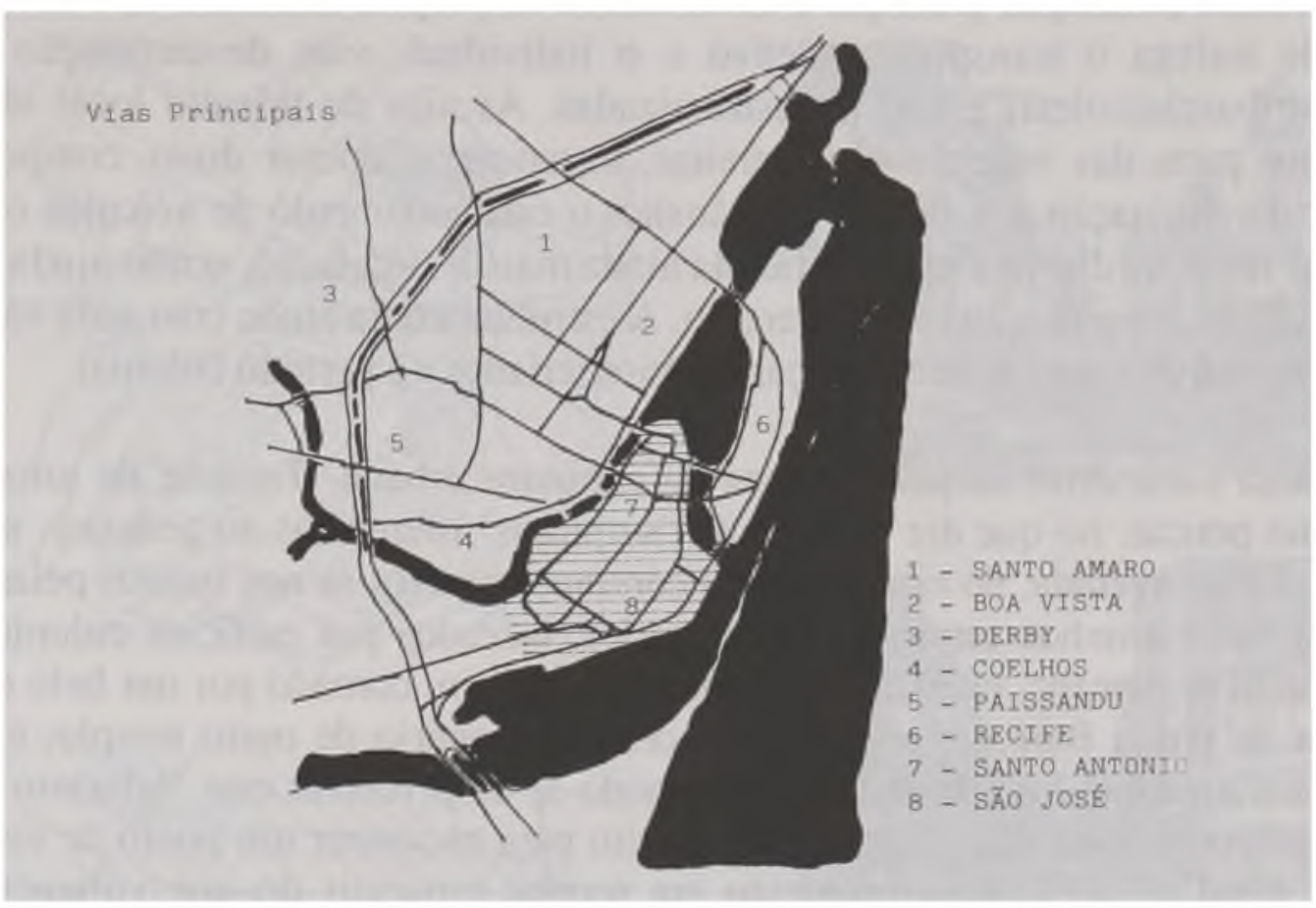

\section{ASPECTOS CONTRASTANTES DA PAISAGEM}
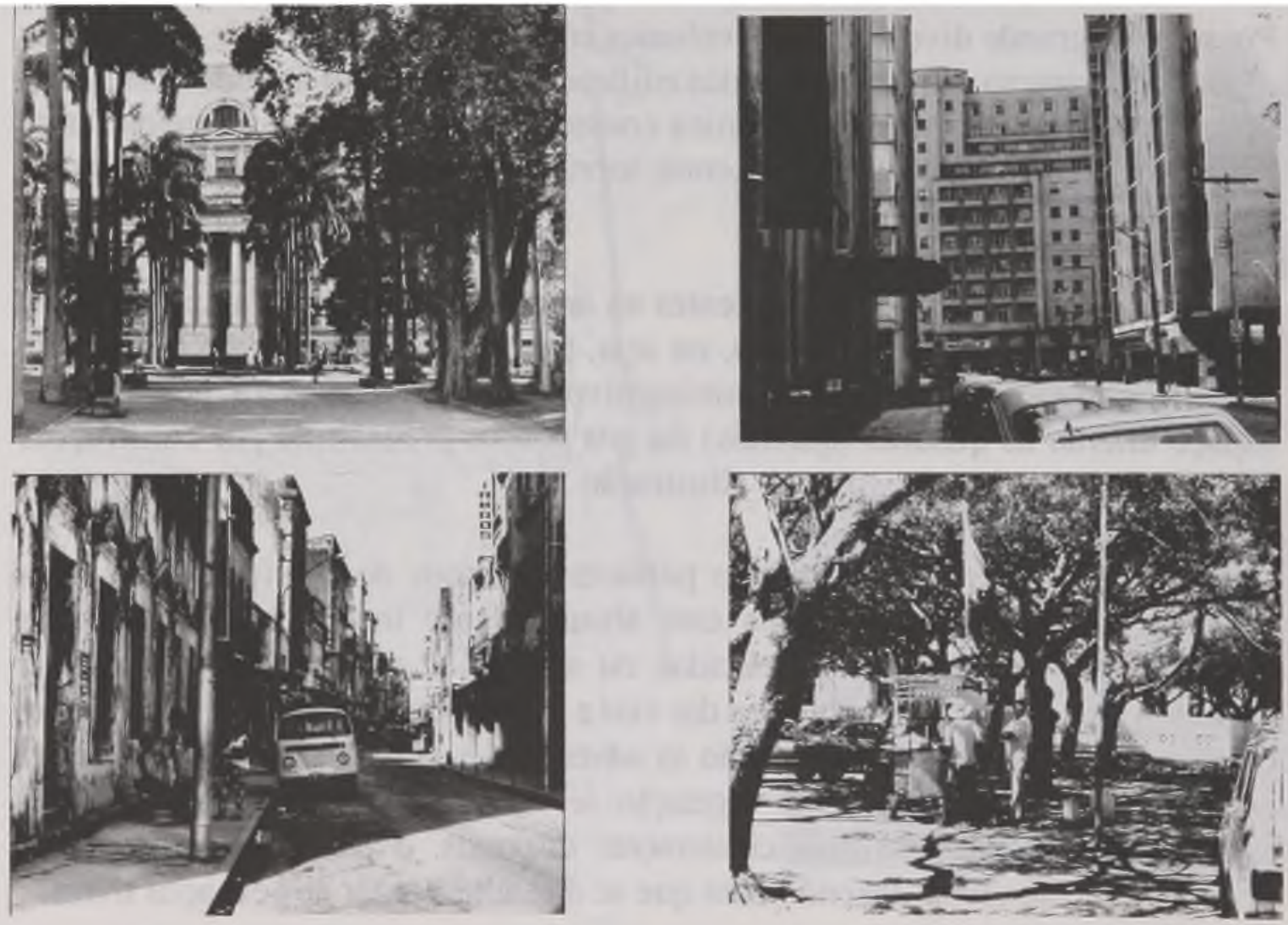
A estrutura de circulação interna da área é definida, pois, por estas grandes avenidas, circulação principal a nível macro na própria estrutura da cidade, por onde trafega o transporte coletivo e o individual, vias de circulação local (distribuição/coleta) e vias pedestrianizadas. As vias de trânsito local são, na maior parte das vezes, muito estreitas, tortuosas, e, apesar disso, comportam, por determinação dos órgãos de trânsito, o estacionamento de veículos em até duas mãos de direção, o que dificulta ainda mais a circulação, sendo ainda o seu estado de conservação muito precário. A estrutura conta ainda com uma série de espaços livres, na forma de praças e pátios, criados no período colonial.

A área caracteriza-se pela riqueza da estrutura urbana. Trata-se de uma área como poucas, no que diz respeito às "surpresas" oferecidas ao pedestre: saindo da grande avenida, do espaço aberto contínuo, penetra-se nos bairros pelas ruas e vielas, caminhos estreitos e sombreados, ladeados por edifícios coloniais, e, quando se percebe, encontra-se diante de um pátio, coroado por um belo exemplar de igreja Barroca: ao longe, a torre campanário de outro templo, e mais outros ainda, todos interligados. Cansando-se de percorrer este "labirinto ordenado" o pedestre não precisa andar muito para encontrar um ponto de referência geral na área, mais traduzido em termos espaciais do que volumétricos, como o rio ou uma grande avenida. (Ilustração 4)

Possui uma grande diversidade de volumes construídos, com grande variação da altura e do número de pavimentos das edificações, bem como a idade destas. sua forma de ocupação do espaço, técnica construtiva, etc. É possível encontrar-se edificaçōes de 1 a 20 pavimentos, entre sobrados geminados e grandes edifícios isolados.

As áreas livres de edificação, existentes na área, restringem-se praticamente aos espaços de livre acesso ao público, ou seja, praças, pátios e vias de circulação, além de edifícios religiosos e administrativos (espaços edificados públicos). $\mathrm{O}$ espaço interno às quadras (quintais) foi aos poucos preenchido por construções irregulares, puxadas, anexos, etc. (Ilustração 5)

A incidência de vegetação em áreas públicas na cidade de Recife está por volta de $0.4 \mathrm{~m}^{2}$ por habitante, índice este absurdamente insuficiente segundo as normas internacionalmente estabelecidas, ou seja, de $12 \mathrm{~m}^{2} /$ habitante. No que diz respeito à área de estudo, a estreiteza das vias e a altura das edificações, compensam. em parte, este "problema" em relação às adversidades climáticas a que a área está exposta. No entanto, quando a vegetação se faz realmente necessária (grandes avenidas), as árvores são insuficientemente dispostas, o que dá mais aridez e insalubridade ao clima, fazendo com que se dificulte o estar nos espaços livres. 


\section{Ilustração 4 - Exemplo de Seqüência de Espaços Livres}

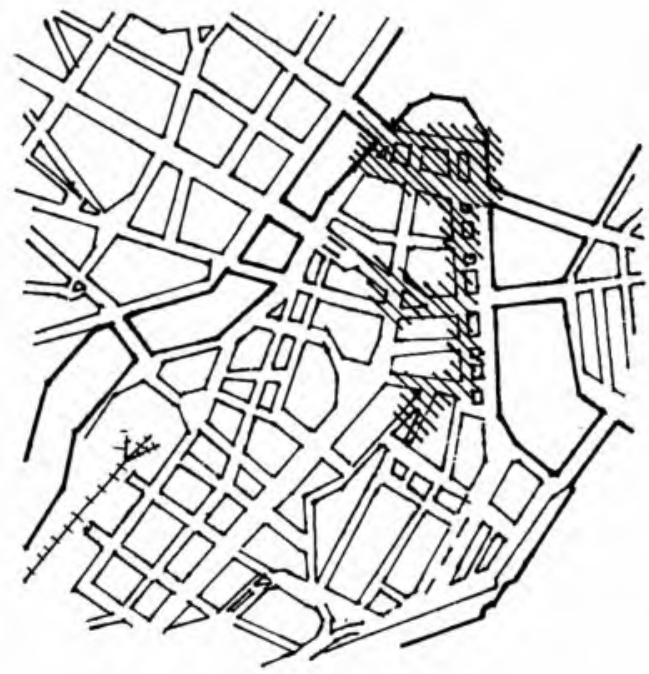

1

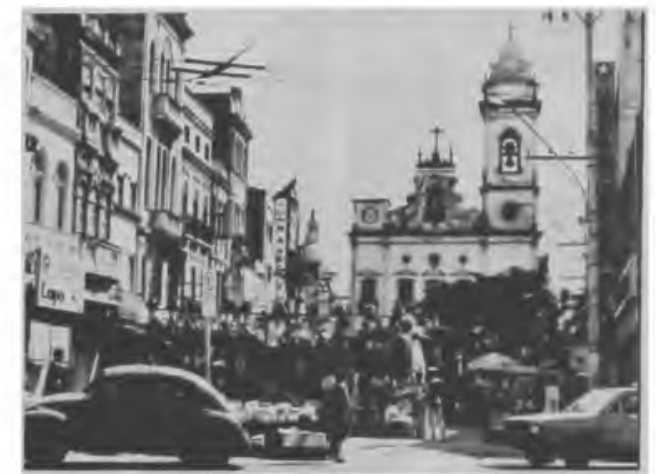

2

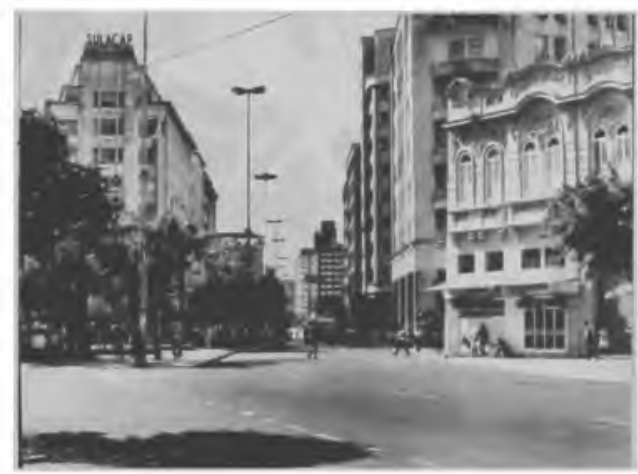

3

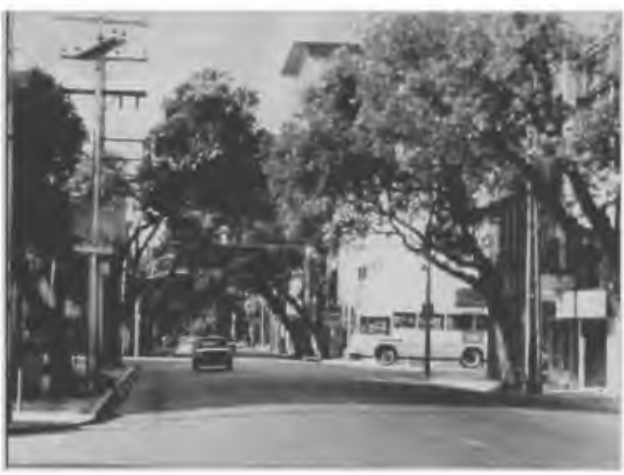

4

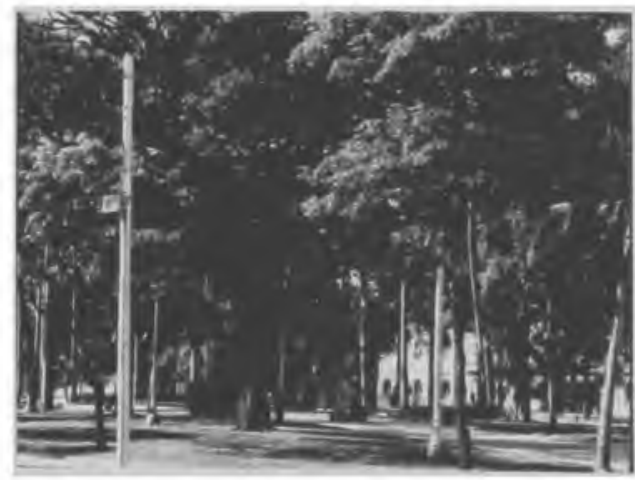


Ilustração 5 - Espaços Livres de Edificações

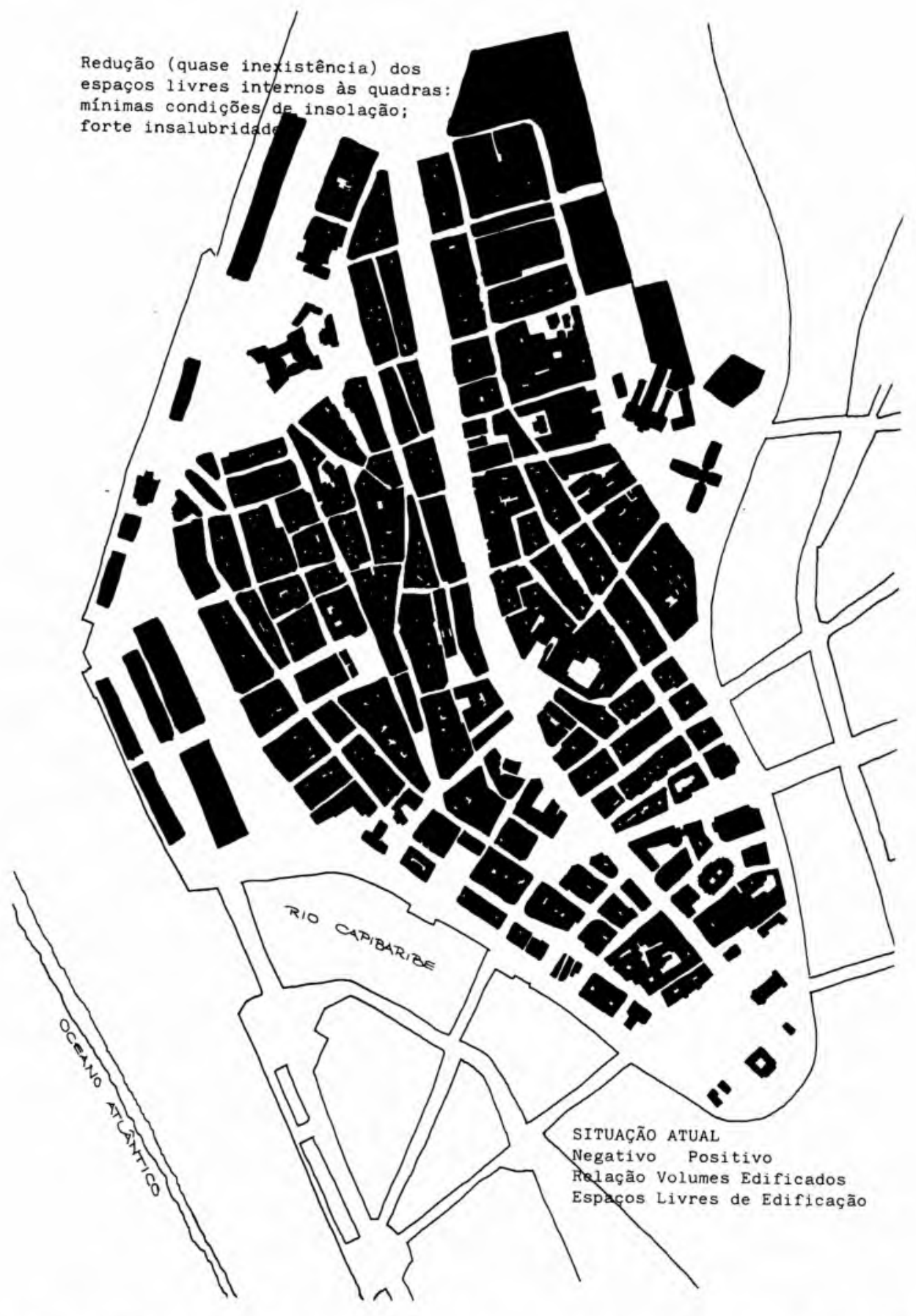

O uso dos espaços livres pela população varia especificamente de acordo com a área e o período de uso. Tais usos subdividem-se em:

circulação de veículos, circulação de pedestres; pontos de encontro/parada; estacionamento de veículos; ocupação por vendedores ambulantes. 


\section{USO DOS ESPAÇOS LIVRES}

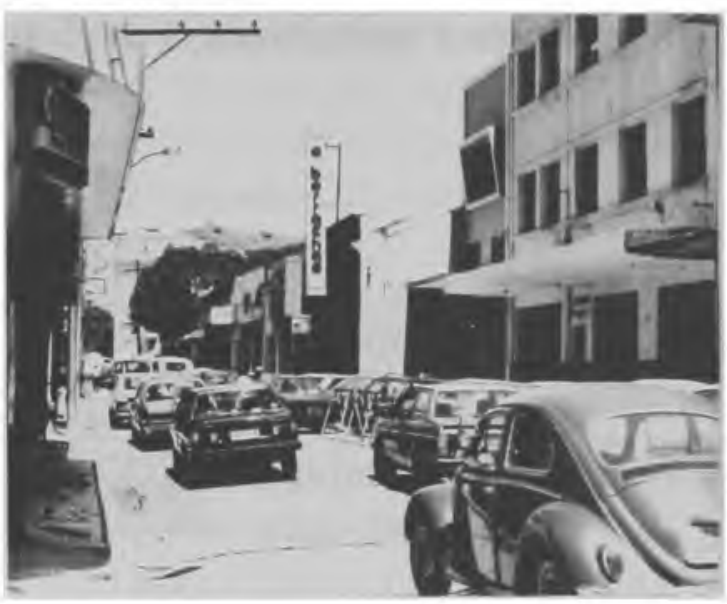

1 - Circulação de veículos

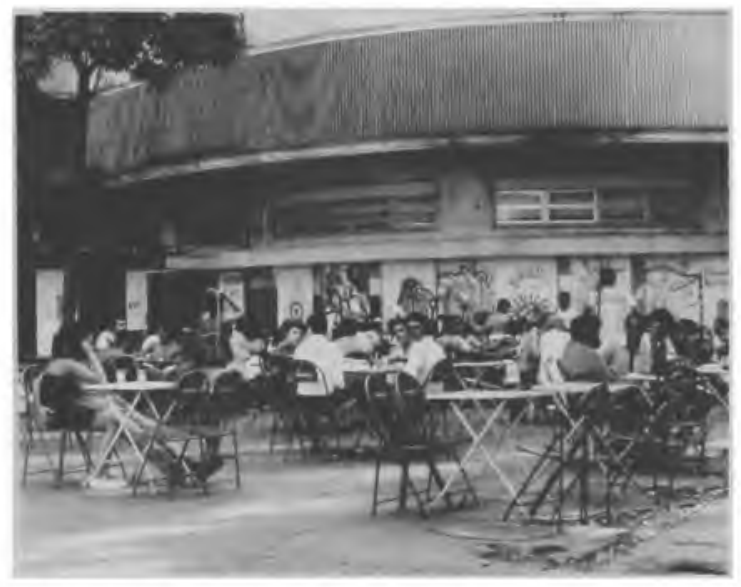

3- Ponto de encontro/parada

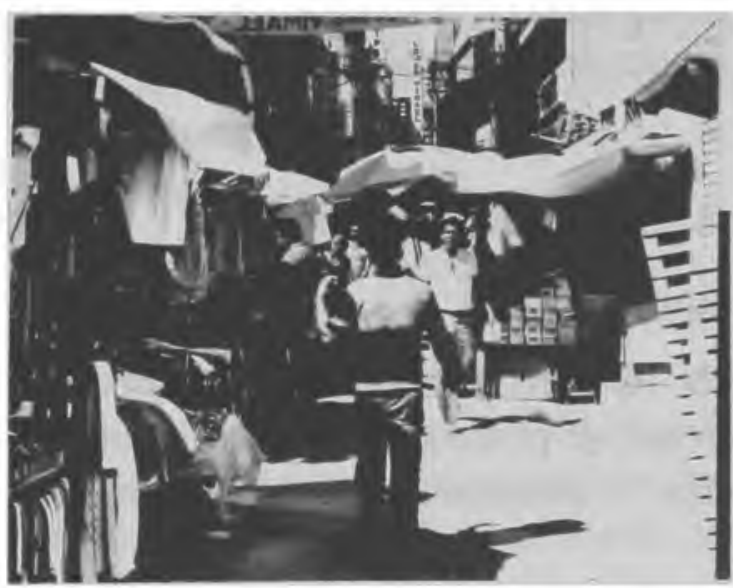

5- Ocupação por ambulantes

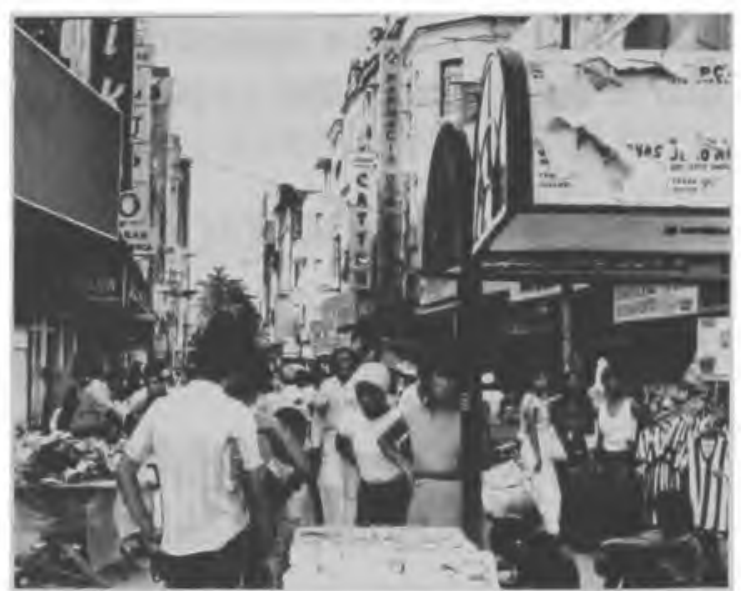

2- Circulação de pedestres

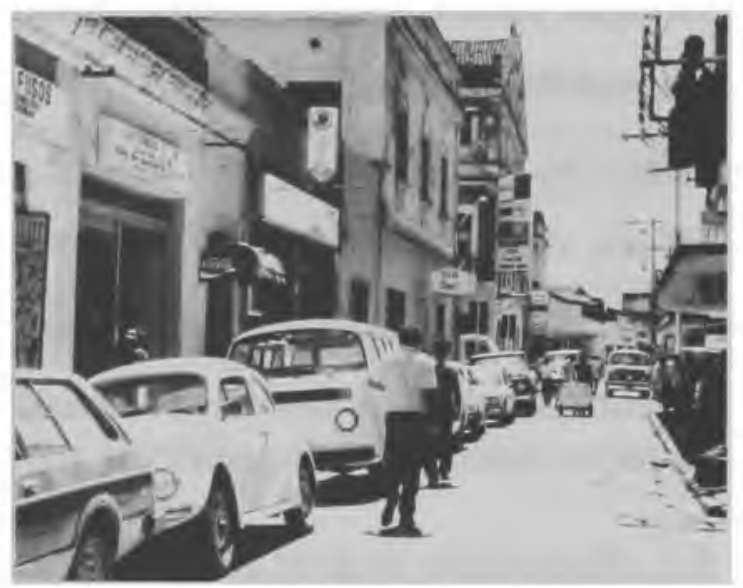

4- Estacionamento de veículos 
A variação de intensidade se faz, por exemplo, pela redução do número de pedestres de acordo com a mudança de uso das edificações, pela redução do número de veículos e aumento do número de pedestres e ambulantes, à medida que se diminui a "calha" (o porte) das ruas.

\section{SISTEMA DE ORIENTAÇÃO E REFERÊNCIA}

\subsection{Gradação da amplitude dos espaços livres de edificação}

Grandes espaços, grandes avenidas, margens dos rios:

Macrodefinidores da paisagem

Macroelementos de orientação

- Praças, pátios, entroncamentos, alargamento de vias:

Microdefinidores de paisagem

Conhecidos pela forma, pelo nome e por edifícios dominantes.

Ruas, vielas e becos:

Elementos de união entre macro e microdefinidores da paisagem

Orientação através de eixos visuais de comunicação com outros elementos (espaços macro e micro; edifícios significativos).

\subsection{Orientação através dos elementos construídos}

Neste caso específico, a definição entre macro e microdefinidores da paisagem torna-se subjetiva e deve ser especificamente aplicada a cada caso. Os elementos edificados que podem possuir o valor de orientação na trama urbana são:

Edifícios mais altos

Edifícios mais importantes (implicaria um conhecimento prévio)

Edifícios religiosos e suas torres/campanários.

Nas ruas estreitas, os sobrados de dois, três ou mais pavimentos em ambos os lados dispostos no alinhamento, fazem com que se perca o referencial geral, por mais importante e imponente que este seja; o transeunte é denominado pela escala e pela atmosfera da via. 